American Journal of Applied Sciences 4 (8): 587-591, 2007

ISSN 1546-9239

(C) 2007 Science Publications

\title{
Marketing Research Merely Reflects The Needs And Wants Of Consumers
}

\author{
Theodossiou George and Kourti Chrisa \\ Technological Education Institution of West Macedonia, Department of Marketing and Quality Control of \\ Agricultural Products, Florina, 53100, Greece
}

\begin{abstract}
In the recent years, marketers have focused their attention on the consumer. The aim is the acquisition of comparative advantage in the market. They have succeeded to develop organizations oriented to the market, and departments that support the competition strategy for the satisfaction of the needs and the wants of the consumers. The golden rule of Marketing says that a product is not sold but answers to a need of the market. To reveal this need question of the following type must be answered: Who will buy the product? What values does the product offer? What new product could be introduced in the market? These and other relative questions are the keys to the decision-making. Today, there are few needs that companies are not aware of.. Thus, they create new needs. The necessary condition of marketing orientation is the knowledge of the consumers and the other factors of the marketing environment that affect enterprising. Results shows that Marketing research reflects the needs and wants of consumers because it contains the research for the behaviour of consumer, the management of risk of the market of a product but the procedure of hypnotic suggestion as well which is considered to be found on a parallel position with the marketing communications. However, the procedure of hypnotic suggestion is still under research.
\end{abstract}

Keywords: Marketing, Research, Interdisciplinary, Discipline, Consumer behavior

\section{INTRODUCTION}

The enterprises want to create value and satisfaction for the consumer. For this to be accomplished, they need a continue flow of information. The starting-point for a lot of products and for marketing plans is the perfect comprehension of the consumer's needs and wants ${ }^{[1]}$. The enterprises require lots of information for the consumers, the intermediaries and the others factors of the market. More and more businessmen see the marketing research not only as a procedure of decision making but also as a strategic good and an instrument of the marketing. In contemporary marketing, the research could prove to be the main strategic advantage. The competitors can copy the equipment, the products and the procedures but they cannot copy the intellectual capital of a business which is the marketing research ${ }^{[2] .}$

A century ago, the size of the enterprises was small and the research was limited at a local level. Nowadays though, the enterprises take action both at national and global level and they need the information about bigger and faraway markets. As the revenues increase, the purchasers become more eclectic and the enterprises must research continually for the satisfaction of their needs and wants taking the global environment under thorough consideration.

Research is the production of prototype results through methodical, rational and scientific search. Within the frame of research we can detect the recording of the case of relationships between natural phenomena. The aim of research is to describe, to explain and to estimate the phenomena, and is characterized by the property of repetition. The marketing research engages in the product mainly, the behavior of the consumers, the retailers, the competitors, the dealers etc. The marketer decides in relation with the possible reactions. The aim is to provoke or to modify these reactions. The marketer is continually facing with an endlessly growing ammount of information that they have to cope with before reaching to the point of decision making.

The Marketing management of an enterprise faces problems in certain space and time. This is the concern of the marketing research, which gathers systematically, analyzes and makes an objection presentation of the elements in relation to the

Corresponding Author: Theodossiou George, Technological Education Institution of West Macedonia, Department of Marketing and Quality Control of Agricultural Products, Florina, 53100, Greece 
problem $^{[3]}$. Most marketing researches are beneficial for business as well as for consumers. Through marketing research are better informed about the needs and desires of the consumers. As a result the provide products and services which create greater satisfaction. Big marketing companies have answers for $4 \mathrm{ps}$ (Product, Promotion, Price, Place) for products which satisfy the demand from consumers ${ }^{[4]}$.

Whereas there are several other studies which do not accept this subject the answer in the specific question is rather positive.

The main object of this paper is basically man or part of the market, his wishes and needs, which transform very quickly. Marketing research is the first step and the basis in taking productive and effective decisions.

\section{THE ROLE OF MARKETING RESEARCH}

Within the procedure of the realisation of marketing research one could possibly face with various challenges. Some of them are:

The distinction between the consumer research and the marketing science: The clarification of the danger of separation between the consumer researches and the marketing science is seen in the concept of stochasticity.

Until recently, the consumer researchers used the small-scale laboratory or by inference from aggregated sales data for testing and supporting the theories of consumer behaviour in response with marketing stimuli. The development of scanner data on the purchases and the daily panel data using the new information systems give the researcher the capability to study the consumer behaviour in response with marketing stimuli in the market. It is possible that the outcomes of scanner-data go beyond the study of consumer behaviour to marketing science literature. The researchers who use scanner-data follow the inductive approach.

They search the data and they try to result to general principles and theories used by marketingmanagers. But, this empirical theory differs in many respects from one study to another when applied. The data are real and in relation with the current observations and the knowledge of diversity are going to be radically revised.

Consumer researchers can explain the empirical results and suggest new experiments to test consumer behaviour theories in the inductive approach. Consumer researchers can guide marketing scientists to the knowledge of the consumer behaviour following and predicting the wants and the needs of the consumers.

The inadequacy of the marketing research to estimate the phenomenon of the haphazard brand choice of the consumer: Zero brand choice behavior presents an augmentation of evidence even though there is not a cognitive carryover in it. Bass et al. ${ }^{[5]}$ shoed that for nine supermarket categories, which consumers often purchase the hypothesis of a zero-order brand choice could not be rejected at the $10 \%$ significance level for $70 \%$ percent of household which is actually a rather amazing amount. This level was also reported for other products like bread, margarine and sugar where it is not an easy task to prove that randomness or zeropoint nature of choice was falsely due to the spreading choices that members of the same family may make, within te total amount of purchase of house hold [6]. In fact, that does not suggest that zero-order and zeroorder stochastic are two identical terms. As Bass ${ }^{[7]}$ observed the process of the making a choice could be determined at a great extend by a large number of variables such as recent advertising, impressions, pointof-purchase, promotions, out-of-stocks, etc, that make a conscious choice appears as random one. The frequencies of each purchase occasion can not be predicted and as a result that choice transforms into a zero order. Bass's alternative hypothesis of a stochastic element in brain, or at least some kind of stochastic process within the procedure of a choice making, must be considered thoroughly since it seems difficult to accept that conditions change so dramatically from one purchase to another. In a paper of Winter and Rossiter

${ }^{[8]}$ have proposed a consumer brand choice model which includes a stochastic elements of a considerable value. This model claims that consumers deliberately change their attitude during a purchase due to a need for variety rather than to a random element in brain. According to this model, consumers develop an individual pattern of purchase for each category of product, which suggests when to purchase in a sense of loyalty to a brand and when to "go stochastic" and choose a brand randomly.

This model can predict the repeats and stochastic selections rather accurately and on the other hand it indicates stochasticity as a considerable factor for consumer brand choice, giving to stochasticity an explanatory stand and content rather than a descriptive one, and pointing out its causal significance.

The estimation of the consumer for the risk of the product: Another dimension that must be taken into consideration in Marketing Research is the concept of 
risk that every consumer market contains ${ }^{[9]}$. It is clear that the theory of risk contained in the products and services correlates with the problems of its management by the consumer ${ }^{[10]}$.

The term perceived risk relates to the personal perception of the consumer before, during, or after the purchase of a product ${ }^{[11]}$. The categories of the "perceived risk" are:

- Fuctional risk.

- Physical risk.

- Financial risk.

- Social risk.

- Psycological risk.

Engel et al. ${ }^{[12]}$ proved that the most important function of the consumer research is in establishing the level of safety that must be considered in decisions concerning the products.

As Rethans ${ }^{[13]}$ proved, the estimation and management of hazards arising from technology have. been of major concern to general public and to a number of governmental agencies. In order to help society cope with the technological risk, risk assessments have been undertaken in many areas. In the consumer arena, risk estimation for products are generally not made public. The studies that are planned by Jacoby and his associates as part of their NSFfunded studies are aimed at answering the question: "Do consumers actually consider health and safety information when making purchase, usage, and disposal decisions regarding technologically innovative products?» Many of the personal decisions that concern the choice of a product correlate with the wish of the person to participate in the risk ${ }^{[14]}$. When solutions like the air bags for automobiles are enforced or the additional foreign substances in foods etc, then these situations are characterized like an involuntary participation of the consumer in risk. While with the study of Slovic et al. ${ }^{[15]}$, who didn't find any important differences in the evaluation of the desired risk, we could assume that this evaluation can play an important role in the consumer behavior. It's logical that the acceptable risk (by the consumers) depends on the freedom of level of choice ${ }^{[14]}$. In the case where the point of view of the people is restricted, the involuntary accepted level of risk might greatly affect the perception of risk and its acceptable levels. The second point of view on which the researchers must pay particular attention is that it is unlikely for the hazard information to surface before the product or products are introduced into the market [16]. This fact could also point up to the activation of the post-marketing control aiming to the assistance for risk evaluation. The characteristic of risk perception is "availability". Thus the consumers can imagine or wish facts that happen often and a large number of factors (like an accident for example) and this way availability could destroy their judgment ${ }^{[17]}$. Overconfidence could affect the risk perception of the consumers and in the level of the accepted risk for a diversity of products.

The marketing researchers who deal with the theory of "risk assessment" move in the area of consumer behavior and therefore this theory reflects the needs and wishes of the consumers ${ }^{[18]}$.

There are five approximations which are utilized to determine the "acceptable risk." They are:

- Formal analysis

- Non-intervention

- Procedural approaches

- Professional standards

- Comparative approaches.

The similarities between Hypnotic suggestion and Persuasive Marketing in consumer research: Marketing research has come to the conclusion that the phenomena of hypnotism offer significant similarities with the results of marketing communications. How do these two communicative research phenomena which aim to the satisfaction of the consumer function? According to Hilgard ${ }^{[19]}$ "there are a lot of continuations between the experiences outside and inside the hypnosis". The hypnosis and Hypnotic-like are about the analysis of the cognitive reality with intellectual concerns of restricted range. The research in persuasive marketing communications can lead to the results of the hypnotic like due to the fact that persuasive marketing includes situations of focused absorption and increasing suggestion.

Persuasive marketing communications and hypnotic -like can also be regarded as a part of a large scale of situations which concern variations of the absorption to an object and the awareness of the surroundings. As a result the research of hypnotic suggestion communications will allow us to comprehend the procedures of marketing research from other view points, which are the following:

- By focusing to the consumer who is exposed to stimuli which can render them prone to the commercial message.

- By considering the consumer as a conscious player who is limited by personal and social hindrances

- By focusing the significance and the impact of the two previous methods to the procedure of persuasion. 
- The procedure of hypnotic suggestion seems to be in a parallel position to the marketing communications which is on a situation of alert and follows a motive, a situation and a response model. On the other hand the hypnotic suggestion is based on a typical situation of ecstasy and differs from the marketing communications in terms of the nature of the reception state and role. However the degree of parity between the two methods remains a subject to be researched. Thus the Marketing Research for the consumer (his needs and wishes), could research the philosophy of hypnosis in order to reveal the phenomenon, which would help to the explanation of the consumer and the procedure of conviction.

The Communication into the interdisciplinary research: There are many theories and views relative to the Marketing Research ${ }^{[9,10, \text { and } 23]}$. The interdisciplinary research comprises the juxtaposition of the abilities of the members of the university community of various disciplines, which integrate the knowledge of a problem giving solutions, which a researcher alone could not give. Very often the multi-disciplinary research is the final product. Most of those who dealt with the interdisciplinary research agree that its main characteristic is not the deep scientific development but an improvement of the human relationships in order to overcome intolerance, fanaticism and the obstacles not only between people but between disciplines as well.

Communication is possibly the most important problem in interdisciplinary research. The involved persons must comprehend the diversity of views, which focus on a problem under research. Without this concept, which demands a high level of tolerance, the interdisciplinary research cannot advance. The interdisciplinary research is focused on the convergence of two disciplines in order to develop the comprehension of the interest of the consumer and the perspective of the social policy.

Interdisciplinary research activities lead to a better knowledge and evaluation of the philosophies that emphasize the perspective of the rules of marketing and the consumer behavior. The horizons of those involved broaden. Problem management is more scientific because all its dimensions are taken into consideration and there is great tolerance between the disciplines $^{[20]}$.

It has been stressed that marketers often manage the consumer not as the subject but as a person that is influenced in order to materialize his goals ${ }^{[21]}$. Interdisciplinary research helps to overcome this prejudice. The field where the interdisciplinary research is focused comprises the behavior of the consumers, their activities for the research of information, the prototypes of food consumption, the satisfaction or not that comes from the consumption of various products or services and the negative behavior and the adequacy of the natural facilitations offered to the consumer. In a conference at the University of Nevada the following fields of research were confirmed in the definite space of "improving consumer competence in family resource use" ${ }^{[20]}$.

- Comparison shopping studies for both goods and services.

- Family expenditure for food, clothing, shelter, services.

- Assessment of non-food items charged to the food budget.

- Comparison of convenience foods and/or prepared foods with those made at home.

- Evaluation of information available to consumers in relation to potential purchases.

- Comparison of costs in different retail outlets.

- Assessment of knowledge regarding consumer credit.

- Attitudes and values of different groups about money and financial management.

- Knowledge of credit costs and available information about credit.

\section{CONCLUSION}

Marketing research has as a greater role than studying the consumer behavior in the crease f sales. Marketers today use a plethora of techniques to study the consumer and market behaviour and the efficiency of Marketing. According to an old Spanish theory "To be a bullfighter, you must first learn to be a bull"[22]. From the previous comprehensive analysis of the methodology it arises that Marketing research reflects merely the needs and wants of consumers because it contains the research for the behaviour of the consumer, the risk management of the market but also the procedure of hypnotic suggestion as it is considered to be found on a parallel position with the marketing communications. The procedure of hypnotic suggestion is still under research and we cannot draw premature conclusions. It is considered that the issues concerning the research of the hypnotic phenomena and persuasive marketing have offered the basis for future development both of theory and empirical research which is related to the marketing research and the communication and the satisfaction of the consumer. 
The social consequences of the connection between the persuasive marketing research and the hypnotic phenomena is a worrying prospective when we realize that the imagination of the consumers has already connected advertisements with subconscious factors.

\section{REFERENCES}

1. Canadian Marketing, 1981: "Principles and Applications", Mc Graw-Hill, p.149)

2. Kotler, P. (1999), "Kotler on Marketing" edt. Free Press N.Y., p.73

3. Grouch, S. and M. Housden, 1999. "Marketing Research for Managers", Oxford: ButterworthHeinemann, pp. 253.

4. Kotler, P. and G. Armstrong, 2001. "Principles of Marketing". Prentice-Hall, Inc., Upper Sddle River, New Jersey 07458

5. Bass, F.M., M.N. Givon, M.U. Kalwani, D. Reibstein, and G.P. Wright 1984, "An Investigation into the Order of the Brand Choice Process," Marketing Science, 4 (Fall), 267-287.

6. Kahn, B.E., D.G. Morrison, and G.P. Wright 1986, "Aggregating Individual Purchases to the Household Level," Marketing Science, 5 (Summer), 260-268

7. Bass, P.M. 1974, "The Theory of Stochastic Preference and Brand Switching," Journal of Marketing Research, 11 (February), 1-20

8. Winter, P.L., and J.R. Rossiter 1988, "PatternMatching Purchase Behaviour and Stochastic Brand Choice: A Low Involvement Product Category Model," Working Paper, Graduate School of Management, University of California, Los Angeles.

9. Michailidis, A., Loizou, E. and K. Polymeros, 2006. Biologic olive oil quality: an illustration of consumers' perception. International Review of Applied Economic Research, 1(1): 35-45.

10. Wright, L.T. and M. Crimp, 2000. The marketing Research Process London: Prentice-Hall, pp. 16

11. Kassarjan, H.H., 1971. Personality and Consumer Behavior. Journal of Marketing Research, November: 409-418
12. Engel, J.F., R.D. Blackwell, and P.W. Miniard 1986, Consumer Behavior (5th d.), Chicago, IL: Dryden.

13. Rethans, Arno 1979, An Investigation of Consumer Perceptions of Product Hazards, Doctoral Dissertation, University of Oregon, College of Business Administration.

14. Wright, P.L., 1974. The Choice of a Choice Strategy: Simplifying vs Optimizing, Faculty W.P

15. Slovic, P., Fischhoff, B., and S. Lichtenstein, 1980. Perceived Risk. In Schwing R.C. and W.A. Albers (Eds.) Societal Risk Assessment: How Safe is Safe Enough? New York: Plenum Press.

16. Venkatesan, M., 1981. Consumer Behaviour and acceptable risk: Some research issues. Advances in Consumer Research, 8: 503-505

17. Gould, J.S., 1992. Parallels between hypnotic suggestion and persuasive marketing communications: insights for new directions in consumer communications research Advances in Consumer Research, 19: 56-61

18. O’ Shaughnessey, J., 1987. Why People Buy. New York: Oxford University Press, pp.161

19. Hilgard, Ernest R. 1965, Hypnotic Susceptibility, New York: Harcourt, Brace \& World

20. Mason, J.B. and H. Goetz, 1978. The problems, pitfalls, and opportunities in interdisciplinary applied consumer research. Advances in Consumer Research, 5: 734-737.

21. Arndt, J., 1977. A Critique of Marketing and the Broadened Marketing Concepts. Paper presented at the Second Macro-Theory Seminar, University of Colorado, Boulder, August

22. Kotler, P., 2003. Marketing insights from A to Z. Published by J. Wiley \& Sons Inc, Hoboken, N. Jersey, USA.

23. Kamenidou, I., Priporas, V. K., Michailidis, A. and S. Mamalis, 2003. Young Consumers' Perception of Food Quality: An Illustration of Greece. Cahiers Options Méditerranéennes, 61: 191-199. 